\title{
Analysis of Seismic Attributes and Band-Limited Inversion for Re-Determining The Hydrocarbon Prospect Zone in Data F3 Netherland
}

\author{
Ayi Syaeful Bahri *, Pegri Rohmat Aripin, Adib Banuboro, Alfaq Abdillah Robi \\ Department of Geophysical Engineering, FTSP, Sepuluh Nopember Institute of Technology Surabaya (ITS) \\ Jl. Arief Rahman Hakim, Surabaya 60111 \\ *Corresponding author: syaeful_b@geofisika.its.ac.id
}

\begin{abstract}
The aim of this study was to determine the prospect zone of hydrocarbons in Dutch F3 field by utilizing seismic attribute analysis and band-limited inversion. The research data used comes from open source that can be downloaded at opendtect.com. Data processing uses Humpson Russel Software (HRS) to perform well to seismic tie and inversion. Interactive Petrophysics Software for well data analysis, crossplot and potential hydrocarbon estimates, and Petrel Software for well tie load data and seismic attribute analysis. Re-determination of the hydrocarbon prospecting zone includes data selection, log and seismic data processing, horizon and fault interpretation, time structure map and depth structure map, and seismic attribute analysis. From each of these stages will be integrated analyzed on the results of workmanship and geological interpretation of the sustainability of the top reservoir target. Based on the results of clay volume analysis using IP software with Gamma Ray as input parameters, it can be seen that the well that has the biggest prospect is the well F02-1 (774-919 meters) and F06-1 (770-825 meters). This is because the volume of sand in the prospect zone of both wells is larger than the other two wells. The hydrocarbon target depth is in the time to 250 to 500 second (time map structure) or 550 meters (depth conversion) with reservoir lithology in the form of shaly sand with gas fluid as filler.
\end{abstract}

Keywords - Seismic Attributes, Seismic Inversion, Reservoir, Hidrocarbon

\section{INTRODUCTION}

To know the potential of hydrocarbon, it is necessary to acquire data in the form of seismic data and well data. Seismic data is performed to produce seismic cross section and to determine the physical properties of rock with seismic inversion method. The inverse seismic method is a method for constructing subsurface models using seismic data as input data and well data as control. In the inverse seismic method, the seismic cross section is converted into an acoustic impedance that represents the physical properties of the rock making it easier to interpret into petrophysical parameters such as to determine lithology and its spread. The accuracy level of lithologic depiction is also influenced by the method used.

One of technique is to correlate wells, because wells have excellent vertical resolution, but not only that we also need help from seismic data, especially attribute seismic analysis to clarify the much needed lateral resolution. With the help of seismic data, wells, and core exploration activities and development of a prospect area can run smoothly. The availability of data in this case is necessary, but the ability of an interpreter to be a major factor in the success of the development activities.
One of seismic method that can be used to characterize the reservoir is the analysis of the attributes of sweetness, in which attribute analysis uses all information obtained from seismic data, either by direct measurement or by calculations and experiential reasons (Taner, 2001). Then also used the band-limited inversion to obtain subsurface lithologic model.

\subsection{Geological Setting}

Field F3 is a block in the Dutch sector in the North Sea. In this field, seismic 3D acquisition has been conducted for oil and gas exploration which was formed in Upper-Jurassic - Lower Cretaceous era. At depths above $1200 \mathrm{~ms}$ there are reflectors formed in the Miocene, Pliocene, and Pleistocene periods. Sigmoidal-bedding on a large scale is easily visible which comprises large-scale fluviodeltaic deposit systems that deplete most of the Baltic Sea region (SA , rensen et al 1997, Overeem et al 2001). 
The delta region consists of sand and shale,

This slice-shaped area represents the material

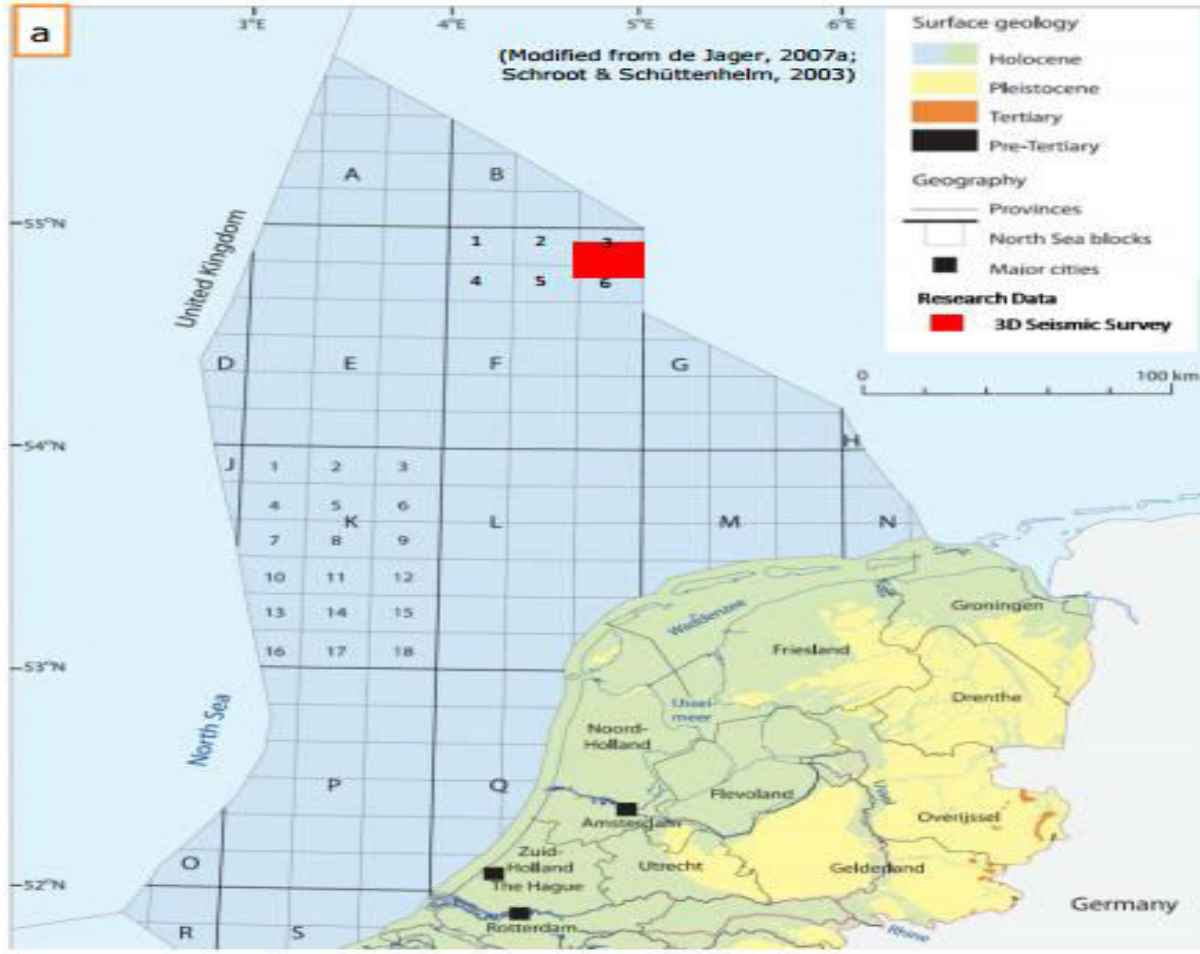

Figure 1. Research location

with overall porosity quite high (20-33\%). In the area there are several carbonate-cemented streaks. A number of interesting features can be observed here. The most striking features are sigmoidal-bedding on a large scale, downlap, toplap, onlap, and cutting structures. Very large portions. In this sedimentary basin the most prominent hydrocarbon source rocks are Westphalian c oalbeds for gas, and Lower Jurassic Posidonia flakes for oil. The last significant regional tectonic drive occurs during the Mid-Miocene, thus forming the Mid-Miocene unity. This surface is now buried in depths that range from about $1000-1500 \mathrm{~m}$. The sedimentary rocks associated with shallow gases discussed in this paper belong to the sequence of clastic sediments after the Mid-Miocene. From the end of the Miocene and beyond, the large number of seismo-stratigraphic units represents a complex delta fan system associated with a pro-delta deposit. Gradually the system evolved into a fluvial delta and alluvial plain, emerging from the east over MidMiocene mismanagement. (Sha, 1991) of a Baltic river system dominated by mature, rough and gravelly quartz sand in the east, and somewhat smooth toward the west near the center of graben with thinning and pinching to the west and east. The overall siltation of the region takes place gradually over time. Fluctuations at sea level together with eustatic movement and displacement of tectonic depocenters result in regressive and transgressive deposits, which are incorporated in the sedimentary cycle. In this cycle, the facies of the sea lie to the west of the land facies (then at the end of the early Pleistocene, this cycle turns to the northwestsoutheast direction). Only in the southernmost part, the Pliocene-Pleistocene deposit extends much older on Tertiary deposits. In the same area, very local coral deposits were formed in the Pliocene-Pleistocene period, similar to the outcropping currently in East Anglia (Cameron et al, 1989a). The shifting coastline of the Netherlands North Sea and its surroundings run from the end of the Pliocene to the next (Sha, 1991) resulting in a wide variety of sedimentation environments and grain sizes. 
The structural development and deposition of the Southern North Sea basin have been well only the S $52^{\circ} 30$ 'area free of the ice mass. Sedimentation conditions have changed completely:

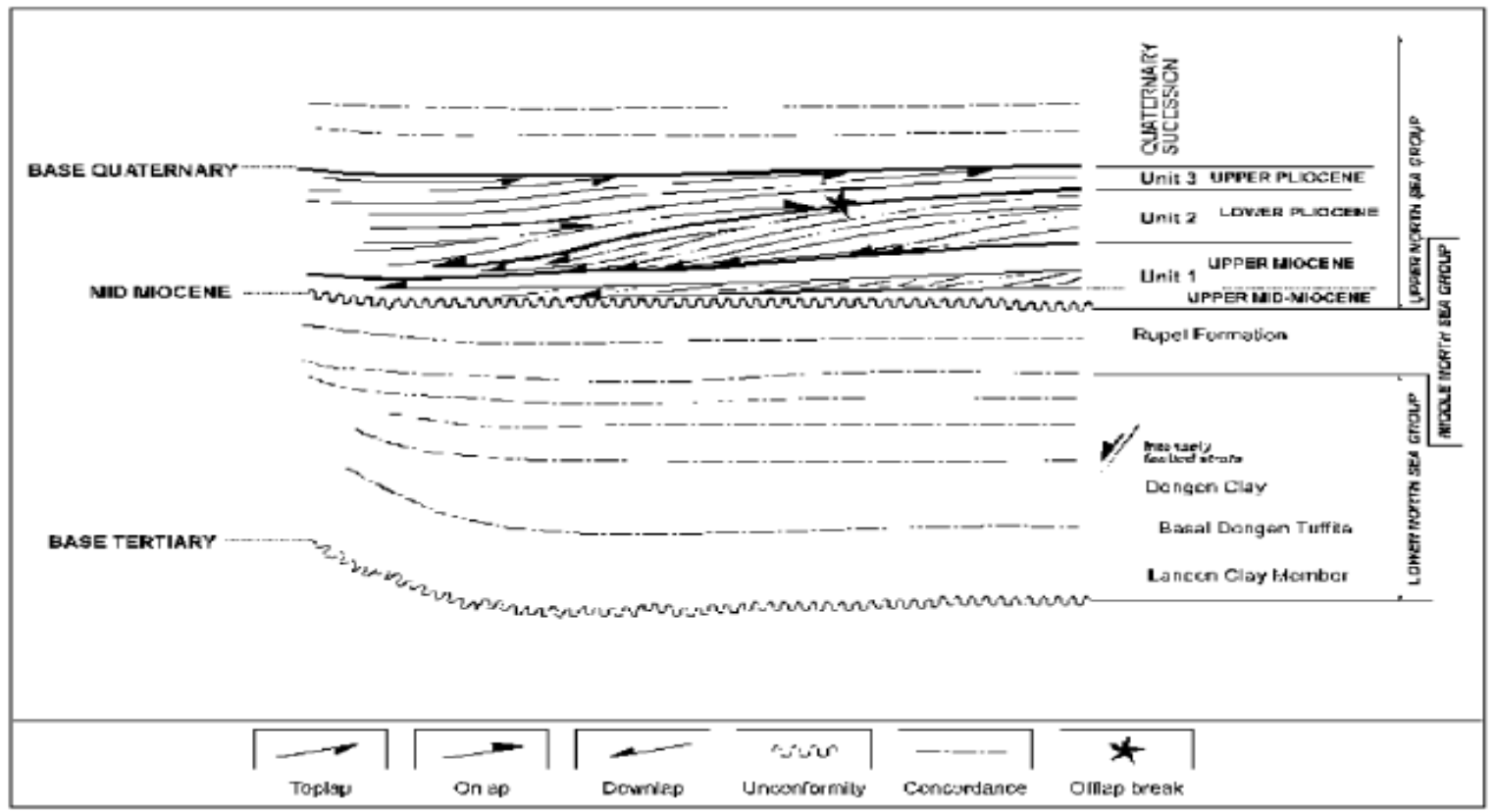

Figure 2. Stratigraphy System

documented. On a large scale, sedimentary basins in the Southern North Sea can be seen as a basin dominated by rifting from the Mesozoic era with the post-rift phase of the Kenozoic ag. Rifting had begun in the Triassic period, culminating in the Jurassic and Early Cretaceous periods with various tectonic extensions of the Kimmerian tectonics associated with the formation of the Atlantic Ocean. The active rifting followed by a post-rift sag phase from the late Cretaceous period to the present, which is largely characterized by tectonic tranquility and decline from the hollow, with the exception of several tectonic compressial movements during the Cretaceous and Tertiary era. During the post-rift phase, most of the basins accumulate a thick layer of deep sediment.

In the southern part of the Netherlands, the main ingredients of Pleistocene klastik originate from the southeastern or southern part, rarely from the western (British sources). At the end of the Early Pleistocene and early Pleistocene of the Middle, the coastline is located in the northern part of the Netherlands. However, occasional transgression disrupts the conditions in the alluvial plains to the south of the north coast of the Netherlands today. This sediment is dominated by sand with little clay and peat. Channeling is widely formed and continuous reflectors are very rare. Sand derived from the Rhine includes half of the northern part of the Netherlands.

The first glacial formation that affected the deposition conditions in the Netherlands North Sea was directly named Glaciation Elsterian (Laban, 1995). The ice mass from Scandinavia and England accumulates and spread over most of the Netherlands, glacial channels reaching a depth of $400 \mathrm{~m}$ are being excavated, especially in the EW belt that passes through the Dutch sector at $53^{\circ}$ and $54^{\circ} 20^{\prime} \mathrm{N}$ (Laban, 1995 The Holsteinian Transgression has resulted in most of the northern part of the Dutch sector formed in sand sheets On a sea transgression with some clays near the boundary of the transgression area.The bridge around the boundary of the Elsterian Element area is gradually displaced.). Sediments generally consist of glacial planar deposits of clay and sandy outwash, whereas in the channel there is a coarse, chaotic basalt covered by laminate, clay, lake deposits associated with clays and sand associated with transgression of the interglacial at the top. Ice supply affects pre-existing faults and tectonic movement of salt, whereas glacial channels interfere with the continued sedimentation and create pathways for liquids and gases.

The ice-induced blockage in the North Sea leads to the diversion of streams previously flowing westward through the Dover Strait into the Bay of Biscay. The next Saali glacial brings Scandinavian ice to the eastern part of the Dutch sector where there are tills, glacial clays and sandy outwash. Glacial ducts are fewer and much shallower, but ice boosts and tongue hollows are more common. The Eemian transgression produces transgression sand. The decline in sea level at the final interglacial Eemian is combined with remnants of the seafloor morphological glacial conditions that form clay sheets deposited in depression, of which the largest is centered around Brown Ridge (Cameron et al., 1989b) 
Clay sheets are able to maintain gas near the

$$
F(\mathrm{t})=f(\mathrm{t})+\mathrm{i} f *(\mathrm{t})
$$

bottom of the sea. Britain's youngest glacial ice, the

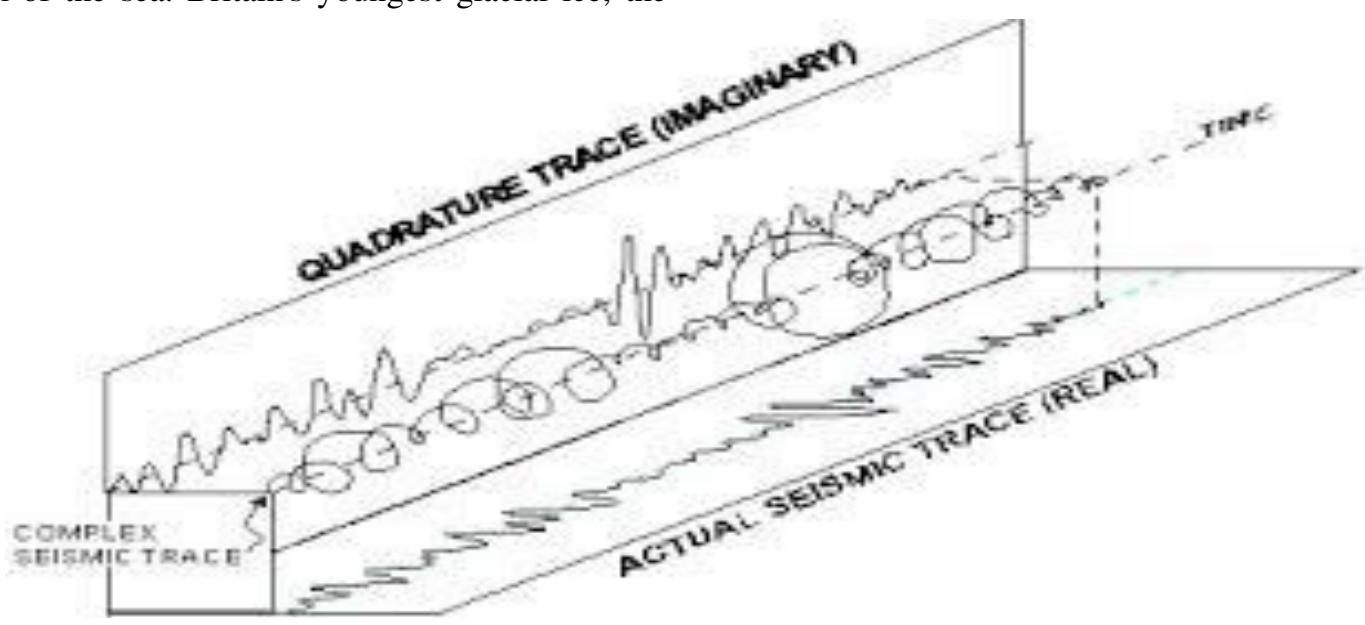

Figure 3. Component of trace seismic (google.co.id, 2015)

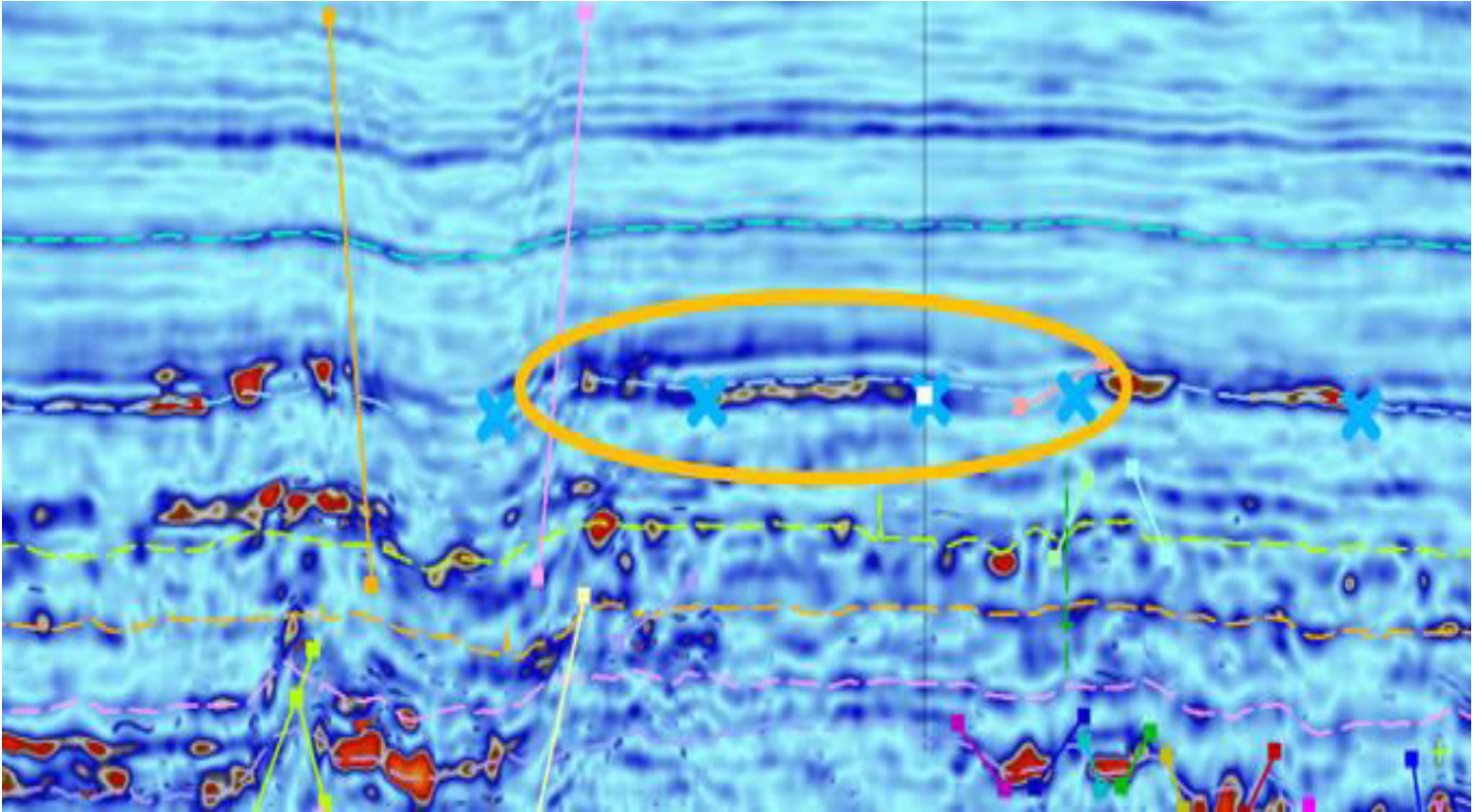

Figure 4. Sweetness attribute in seismic data (Rahman, 2015)

Weichselian, which covers the NW of the North Sea of the Netherlands causes deposits composed of clays, sand and glacial and glacial channels. Dogger bank consisting of glacial sand with a considerable thickness reshaped by the next transgression. Elsewhere, beyond the ice boundary, discontinuous sand blown by wind and drains.

\subsection{Seismic Attributes}

Seismic attributes are defined as the quantitative and descriptive characterization of seismic data that can be directly displayed on the same scale as the initial data (Barnes, 1999). Seismic attributes are needed as a tool in seismic interpretation to show an unseen anomaly clearly from normal seismic data.

Complex seismic trace signals can be written: where $f(\mathrm{t})$ is real trace of seismic, $f^{*}(\mathrm{t})$ is quadrature, which $f(\mathrm{t})$ slided in 90 degrees.

An imaginary component is obtained by performing a Hilbert transform on a real seismic tray:

$$
H(t)=1 / \pi * f(t)
$$

where : $*=$ convolution ; $f(\mathrm{t})$ real trace of seismic ; $\mathrm{h}(\mathrm{t})=$ imaginer trace.

There are many type of seismic attributes: instantaneous amplitude, instantaneous phase,instantaneous frequency, and other with their usability.

\subsubsection{Amplitide Attributes}

The most basic attribute in a seismic trace is amplitude. Initially seismic data is used only to analyze the structure only, since the amplitude is 
only seen based on its presence instead of the contrast value at time. However, at this time the original amplitude value (amplitude attribute) can be derived from the seismic data. The amplitude attribute can identify parameters such as gas and fluid accumulation, gross lithology, unconformity, tuning effects, and sequence stratigraphic changes. Therefore the amplitude attribute can be used for facet mapping and reservoir properties.

In general, amplitude response has a high value if the environment is rich in sand compared with a rich environment of shale. Thus the amplitude map can see the difference in sandstoneshale ratio more easily.

Generally the derived type of attribute amplitudes is derived based on statistical calculations. Therefore, the amplitude attribute is differentiated to 2 , ie, primary amplitude and complex amplitude.

\subsubsection{Sweetness Attributes}

Basically, the attribute of sweetness is ratio between instantaneous amplitude with instantaneous square root of the frequency. The presence of $\mathrm{HC}$ in a formation shown by strong amplitude and low frequency content. This attribute helps to indicates the fluid contacts that occur in a formation. Here is an example of applying sweetness attributes to seismic data.

\section{METHOD}

There are 4 well data are used in this reasearch, they are well F02-1, F03-2, F06-1 and F034. This well consists of several data ie log density, gamma ray $\log$, porosity $\log$ and sonic $\log$. Furthermore, another well data that use are Tops and Cekshot data. 3D seismic data with inline classification 100 to 750,300 to 1250 crosslines, inline spacing 25 meters and sampling rate 0-1848 ms. Data processing was performed using HRS software to perform well to seismic tie, Interactive Petrophysics for well check, crossplot and approximate hydrocarbon potential, and Petrel software to load well tie, attribute and inverse data.

Following methodology in this reasearch includes some steps such as data collection, log and seismic data processing, horizon and fault interpretation, creation of time structure map and depth structure map, and seismic attribute analysis.

From each of these stages, author make integrated analyzed on the results and geological interpretation of the reservoir target continuity. Here's a diagram of the following methodology.

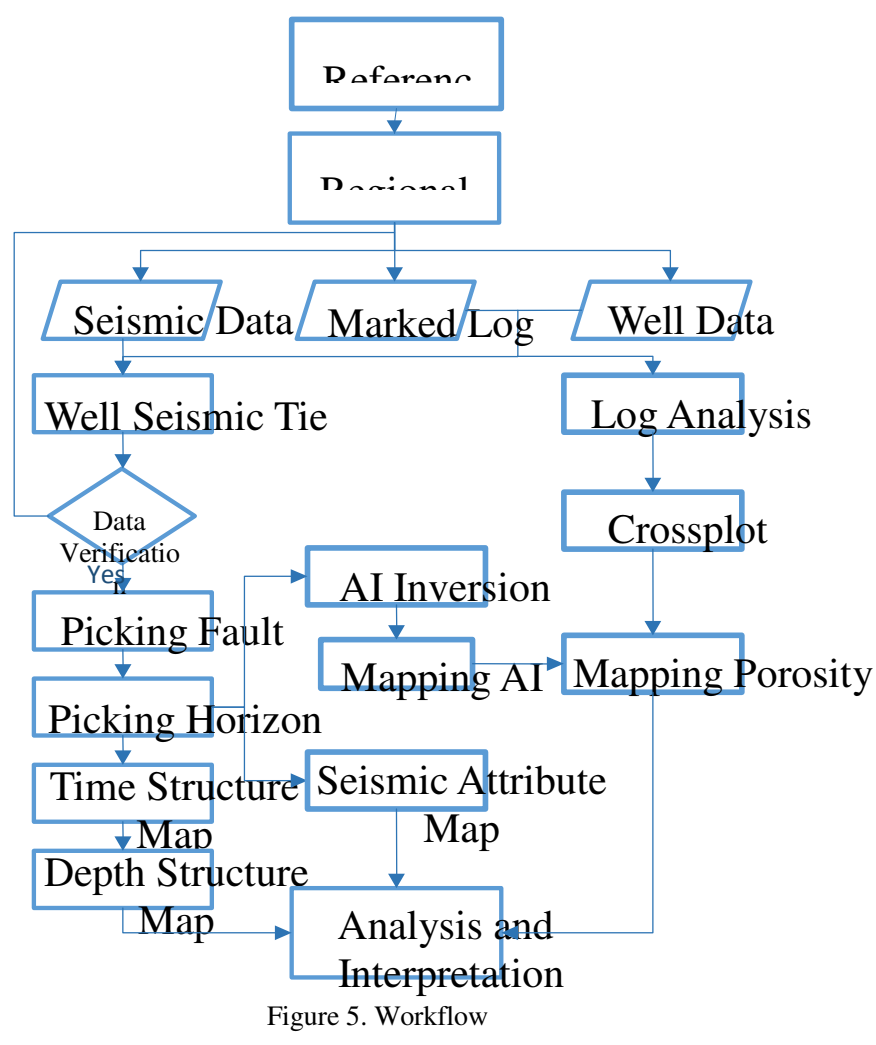

III. RESULTS AND DISCUSSION

\subsection{Seismic Well Tie}

Seismic well tie is a tie process between well data and seismic data. The purpose of this process is to know the prospect zone based on well interpretation and geological marker in the seismic. This process make well data into seismic data domain , where well domains are depth in meters and seismic domains are time at miliseconds.

A synthetic seismogram is needed to convert the well data domain into a time domain. Synthetic seimogram is the result from convolution product of the reflex coefficient with the wavelet. Wavelets are obtained from the extraction of seismic data in around the window range in predicted zone of the reservoir. The window is used in this extraction is about $450 \mathrm{~ms}$ up to $1450 \mathrm{~ms}$ and the wavelet length is extracted about $200 \mathrm{~ms}$. Bandpass Wavelet is used with frequency $5 \mathrm{~Hz}, 10 \mathrm{~Hz}, 60 \mathrm{~Hz}, 80 \mathrm{~Hz}$. Here is a wavelet used to create synthetic seismograms.

This process purpose to get near-actual results, because the frequency of the seismic waves becomes smaller with depth. So it takes a frequency that only presents in the steep reserve alone. The extracted wavelet with a reflection coefficient make a convolution to create a synthetic seismogram to be used in a well tie seismic process. Before doing well tie seismic process, well data ( $p$ wave) is converted first from depth domain into time domain by using checkshot data. 


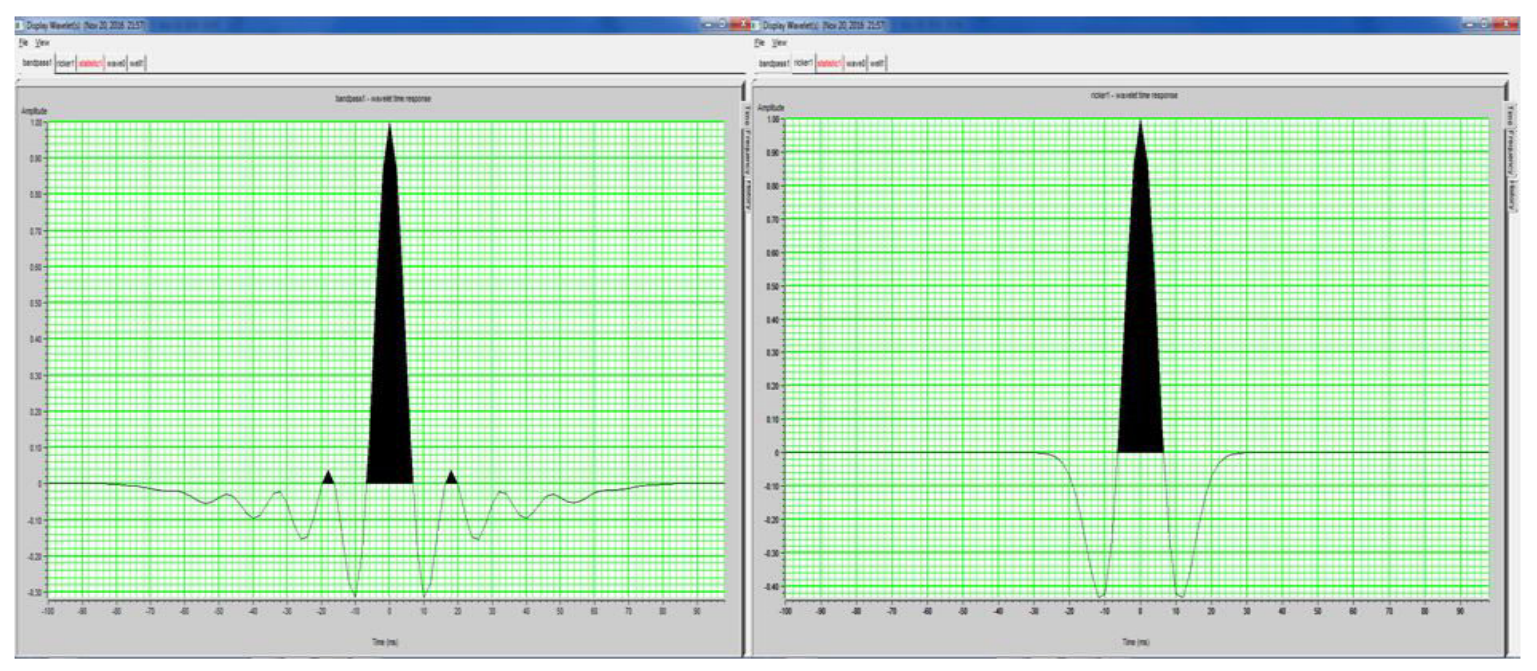

Figure 6. Wavelets used for the manufacture of synthetic seismograms. Wavelet Bandpass (right), Wavelet Ricker (left)

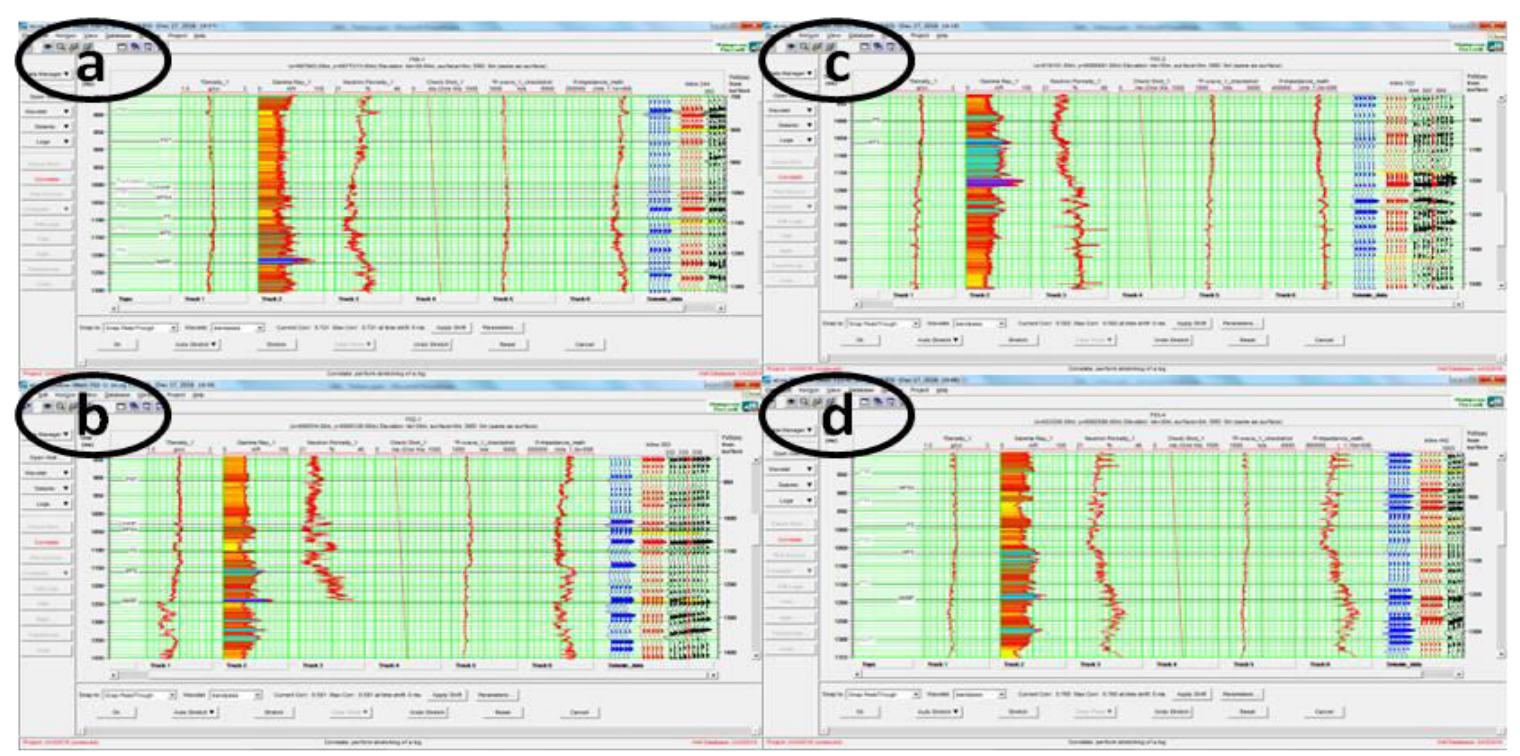

Figure 7. Wells and seismic well tie results; (a) F02-1 with a correlation of 0.581; (b) F03-2 with correlation 0.502; (c) F03-4 with correlation 0.706; and (d) F06-1 with correlation 0.721

In the F02-1 well the wavelet length extracted in the window is $190 \mathrm{~ms}$ from the total wavelet length of $550 \mathrm{~ms}$. In the F03-2 well the wavelet length extracted in the window is $250 \mathrm{~ms}$ from the total wavlet length of $550 \mathrm{~ms}$. In the F03-4 well the length of wavelet extracted in the window is $140 \mathrm{~ms}$ from the total wavlet length of $550 \mathrm{~ms}$. In the F06-1 well the wavelet length extracted in the window is $270 \mathrm{~ms}$ from the total wavlet length of $550 \mathrm{~ms}$.

The width of window is used $550 \mathrm{~ms}$ in the target area. While the wavelet length is extracted 120 ms. The width of window should not be smaller than the width of extracted wavelet so that the synthetic seismogram obtained is sufficiently depicted. Approximately the width of window is three times larger than the wavelet length, in order for the wavelet to be obtained precisely. The dominant frequency is used in this wavelet is $60 \mathrm{~Hz}$, while the phase used is the zero phase. The polarity is used in this wavelet extraction is normal polarity. The extracted wavelet is then convoluted with a reflection coefficient to create a synthetic seismogram to be used in the well to seismic tie process. Before doing this well to seismic tie process, well data ( $p$ wave) is first converted from depth domain into time domain by using checkshot data. Well to seismic tie process is much influenced by shifting, squeezing and stretching.

Shifting is the process move all components of the seismogram to the desired place. This process due to the difference of datum between seismic data and different well data. Therefore shifting should be done. The shifting process performed in this study is about 1-5 ms. In other side, stretching and squeezing is a process of stretching and compressing between two adjacent amplitudes in the seismogram data. In this stretching-squeezing process, it does not exceed 5\% of p-wave changes or interval speeds. This process is used because of the inaccuracy of the migration process on seismic data processing. Because the concept of migration is to move the reflector to the real position, if this process is not accurate it will 
The Third International Conference on Civil Engineering Research (ICCER)

August $1^{\text {st }}-2^{\text {nd }} 2017$, Surabaya - Indonesia

affect the location of the reflector. Therefore, stretching and squeezing process is done.

\subsection{Prospect Analysis Based on Log Data}

The prospect zone in this F3 block is limited between FS8 and MSF4 areas. This is proven from lithology analysis from well crossplot. The prospect zone is evaluated from some log data analysis, seismic analysis, and geological condition. In this research used 4 well data where each well has various data $\log$, but the type of log that will be used in this research is only gamma ray, sonic, density, and porosity $\log$. Cross plot is used to find out the location of the reservoir prospect from the log data, cross plot is also useful to determine the marker when will do picking horizon, crossplot is done between two logs on $\mathrm{X}$ and $\mathrm{Y}$ axis of the axis while the $\mathrm{Z}$ axis as depth control, gamma ray log gives strong signal to the existence of shale and sand where shale has a high gamma ray value while sand has a low gamma ray value. As a correlation to seismic data then crossplot is also finish by using AI log data.

In the crossplot above (Figure 8) example it is assume that the sand zone is in the boxed area. Here is a recap of the data range of physical parameters at 4 well.

\begin{tabular}{|c|c|c|c|c|c|}
\hline No & $\begin{array}{l}\text { Well } \\
\text { Name }\end{array}$ & Depth & $\begin{array}{l}\text { Gamma } \\
\text { Ray } \\
\text { (API) }\end{array}$ & $\begin{array}{l}\text { PHIE } \\
(\%)\end{array}$ & $\overline{\mathrm{AI}}$ \\
\hline 1 & F02-1 & $\begin{array}{l}774- \\
919\end{array}$ & $28-40$ & 0.25 & $\begin{array}{l}\text { 3.9E6- } \\
5.7 \mathrm{E} 6\end{array}$ \\
\hline 2 & F03-2 & $\begin{array}{l}874- \\
1000 \\
\end{array}$ & $26-57$ & $\begin{array}{l}0.25- \\
0.3 \\
\end{array}$ & $\begin{array}{l}3.8 \mathrm{E} 6- \\
5.5 \mathrm{E} 6\end{array}$ \\
\hline 3 & F03-4 & $\begin{array}{l}778- \\
1330\end{array}$ & $10-30$ & $\begin{array}{l}0.25- \\
0.3 \\
\end{array}$ & $\begin{array}{l}5.9 \mathrm{E} 6- \\
6.2 \mathrm{E} 6\end{array}$ \\
\hline 4 & F06-1 & $\begin{array}{l}874- \\
1000 \\
\end{array}$ & $24-54$ & $\begin{array}{l}0.3- \\
0.4 \\
\end{array}$ & $\begin{array}{l}\text { 3.7E6- } \\
4.2 \mathrm{E} 5\end{array}$ \\
\hline
\end{tabular}

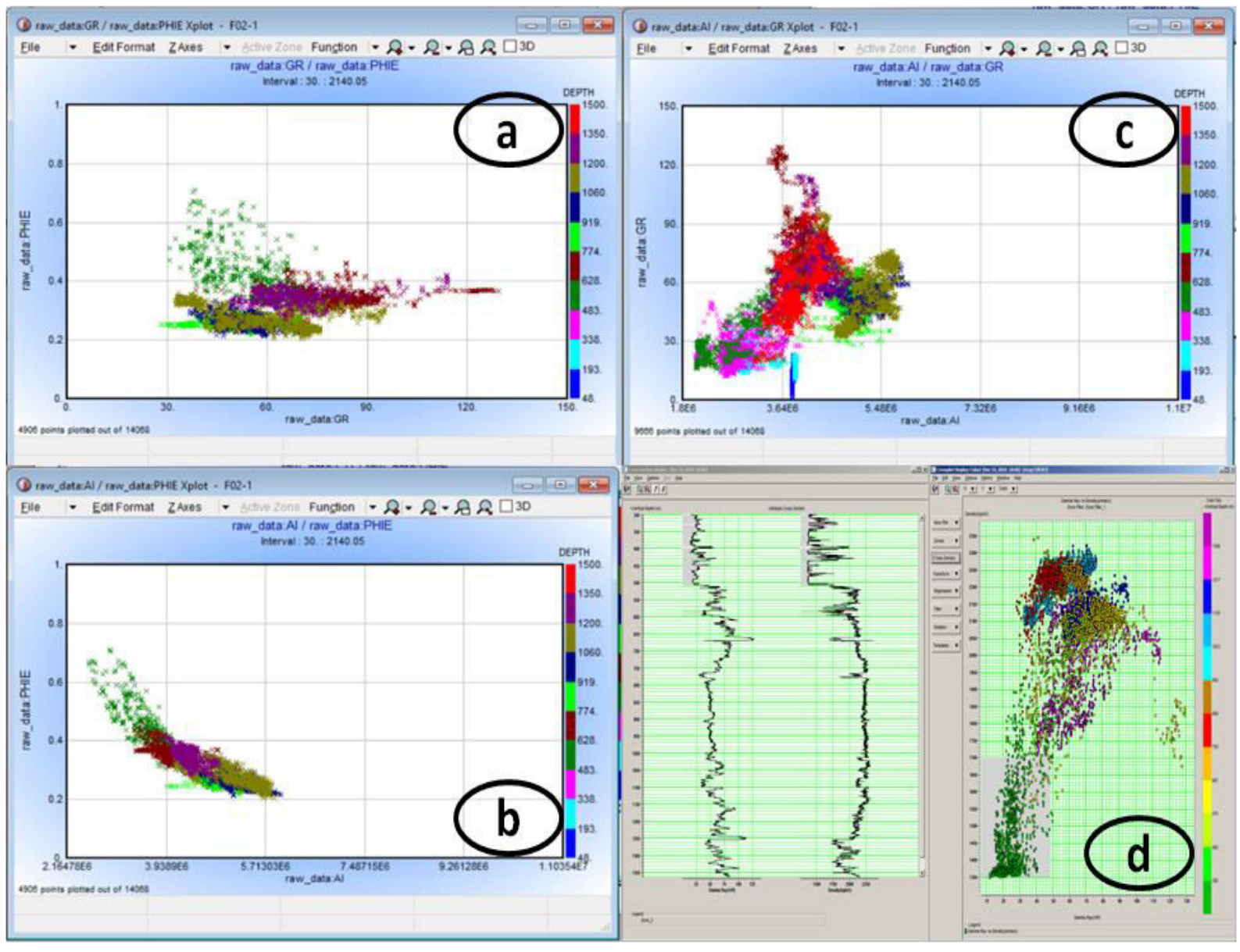

Figure 8. Crossplot in well F02-1 (a) GR vs PHIE; (b) AI vs PHIE; (c) AI vs GR; and (d) GR vs Density

Tabel 1. Analysis of Well Data Log 
The Third International Conference on Civil Engineering Research (ICCER) August $1^{\text {st }}-2^{\text {nd }}$ 2017, Surabaya - Indonesia

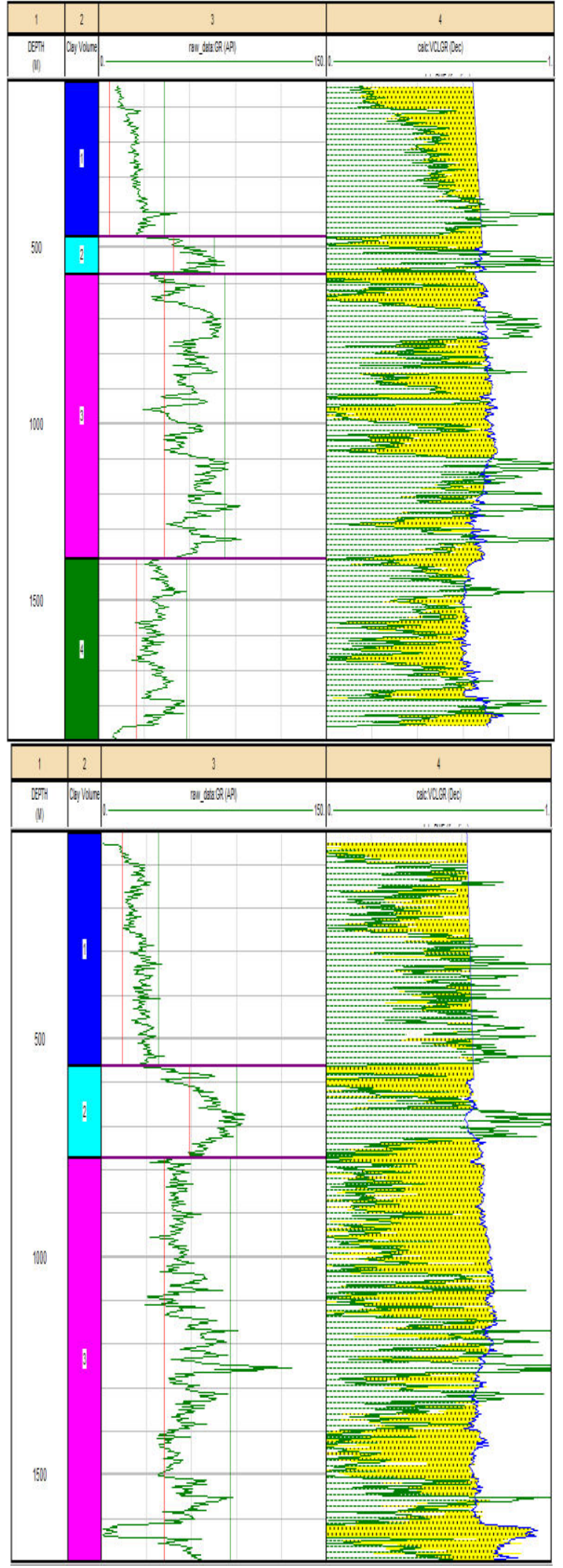

Figure 9. Analysis of Volume Clay in F03-4 (top) and F06-1 (bottom)

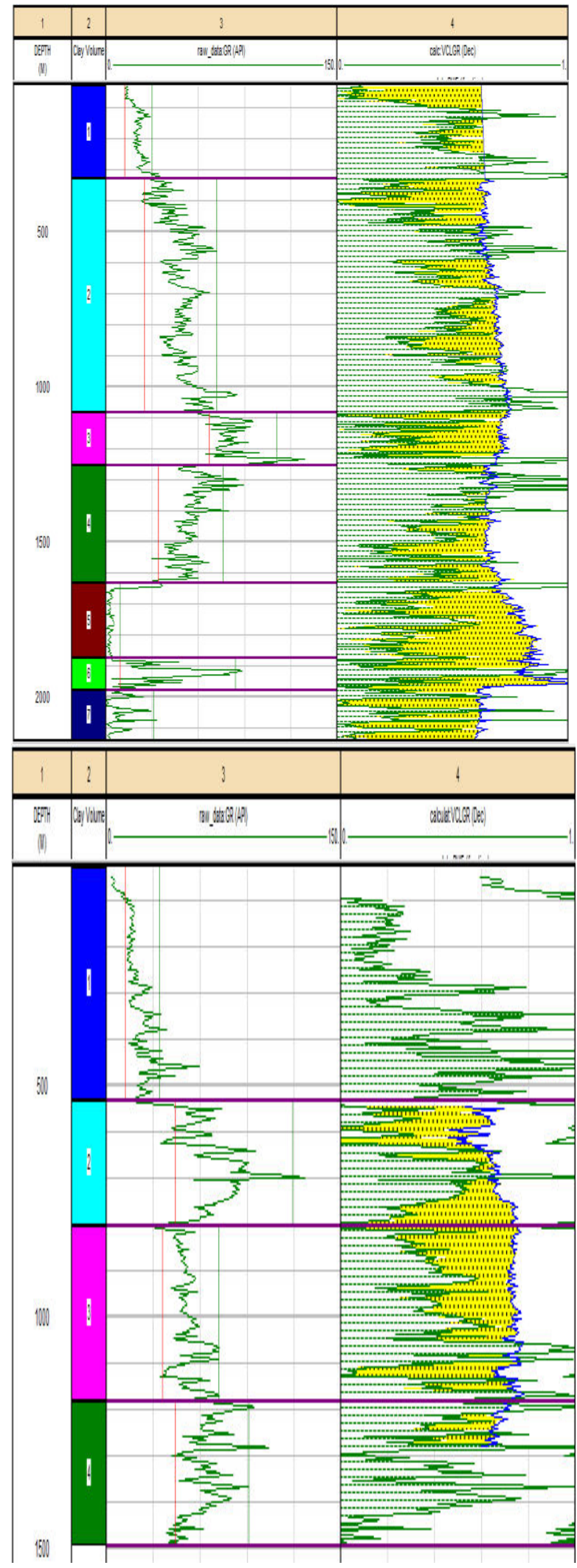

Figure 10. Analysis of Volume Clay in Well F03-2 (top) and Well F02-1 (bottom) 
Well log data Analysis can not finish optimally analysis performed, the existence of this fracture

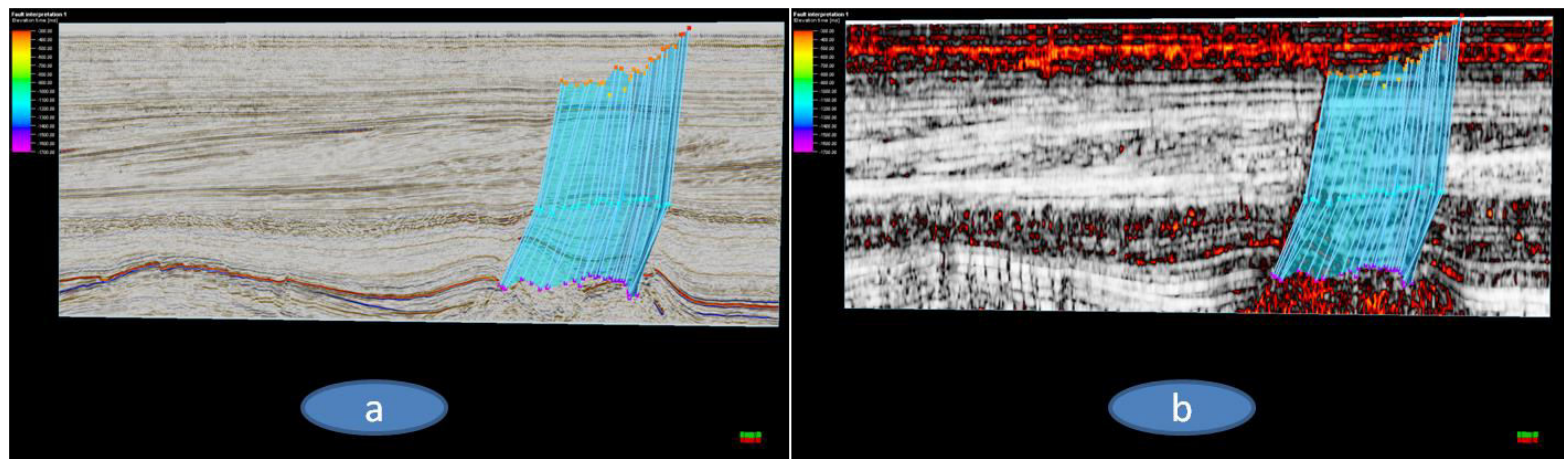

Figure 11. Picking fault process; (a) seismic section and (b) using variance attribute

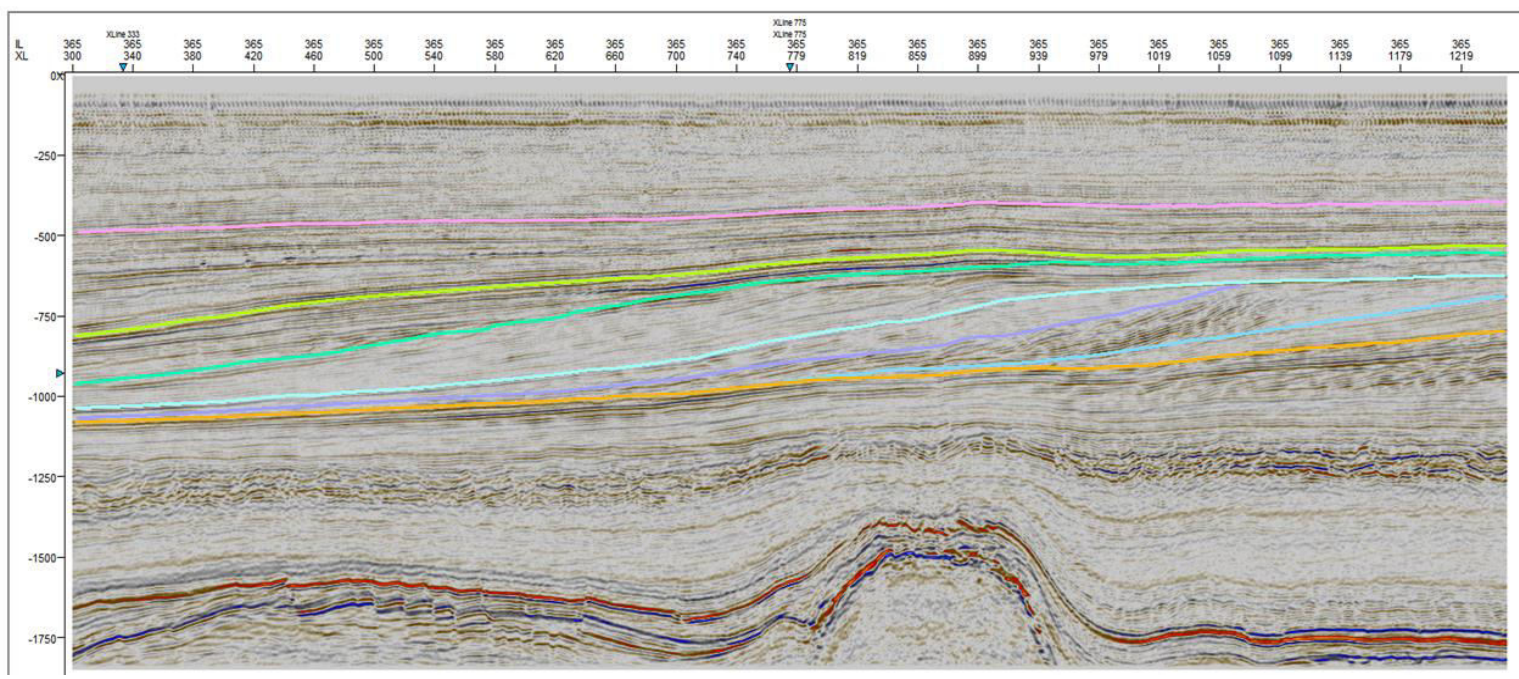

Figure 12. Horizon of F3 data

because of limited data. However it can be seen from several crossplot data indicating that the reviewed prospect zone is at a depth of 800-1100 meters. Based on the results of clay volume analysis with Gamma Ray as input parameters, it can be seen that the well that has the greatest prospect is the well F02-1 and F06-1. It happen because the volume of sand in the prospect zone at both well is greater than the other two wells.

\subsection{Analysis of Prospect Zone Based on Seismic Data}

Fault Picking is performed on a visible horizontal shift and forwarded to the vertical shift zone. In this process we applied the variance attribute analysis of the seismic section. This attribute displays discontinuities in seismic data identifying a fault or a fault. Picking cesareous is done in the seismic cross section shown in the Figure 15 where there is a difference in color value of amplitude.

From the seicmic cross section that has been picked fault, we can find out a major fault. Major fault is directed from the North to South with a slope of approximately approximating $10^{\circ}$. According to the analysis of the slinkend slide this fault is known as a reserve fault (fault up) also found a minor fault fracture located near the major fault. From the allows as an upward migration path of hydrocarbons resulting from higher pressure lower.

Analysis for the horizon, in this processing horizon that used from obtained horizon from the initial data, so that in the process this time utilizing the default data from the rawdund rawdata downloaded. Horizon obtained are FS6, FS7, FS8, MFS4, Top-Foreset, Truncation, and Shallow.

In this processing, to get a cross section of Time Structure the author utilize the horizon from rawdata. This map shows the height difference of each horizon or formation which can be utilized in facies analysis or also the sedimentation process. In addition, maps in this time domain can also help us in fault zone analysis or fractures. The results of Time Structure Map on each horizon seen on figure 13.

For determain the depth structure map, we use the Time to Depth Convertion method from the time structure map. This conversion is associated with checkshot data from well data. Conversion method that used is single function, where this method utilize parameter of cheksoot data. From this map can be obtained the information from depth target zone obtained which is very concerned about the horizon made in the beginning. The result of time map conversion to depth map is shown in figure 14 
The Third International Conference on Civil Engineering Research (ICCER) August $1^{\text {st }}-2^{\text {nd }}$ 2017, Surabaya - Indonesia

\subsection{Seismic Inversion}

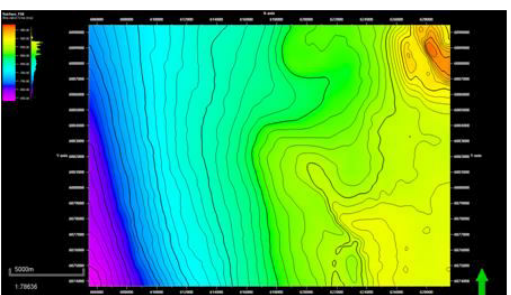

a

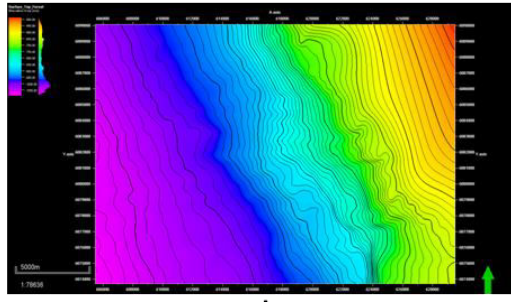

d

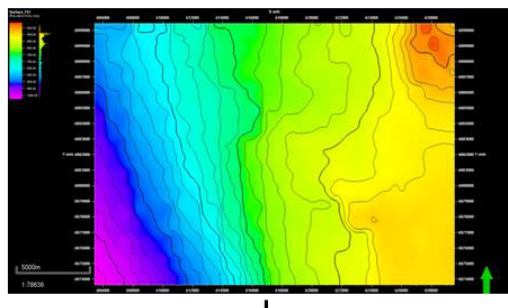

b

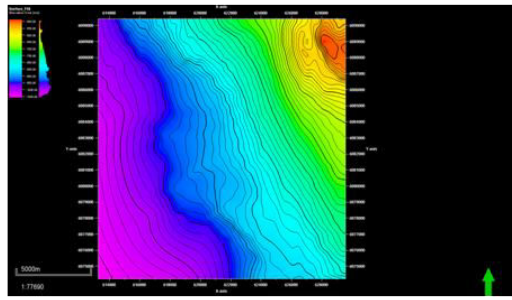

e

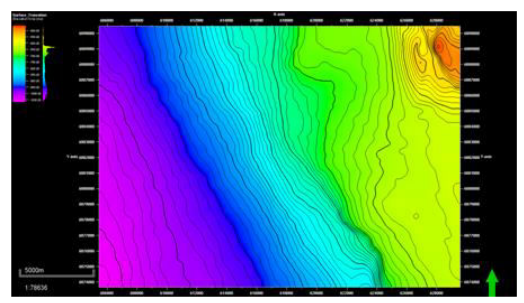

C



f

Figure 13. Time Map Structure; (a) FS8; (b) FS7; (c) TRUNCATION; (d) TOP-FORESET; (e) FS6; and (f) MFS4

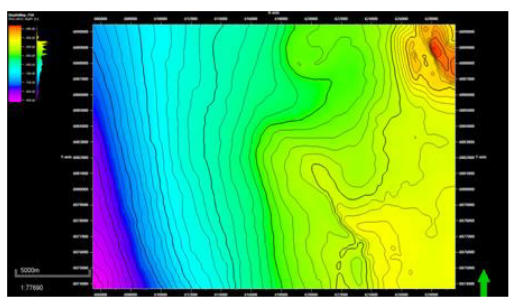

a

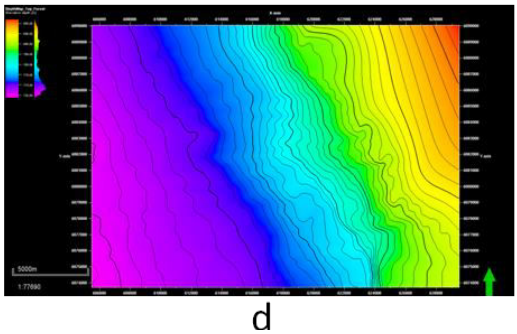

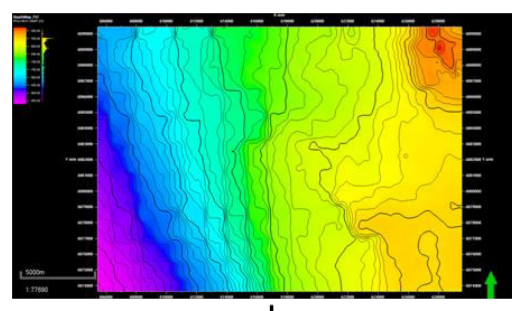

$\mathrm{b}$

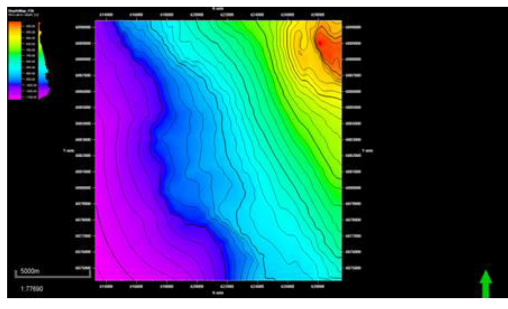

e

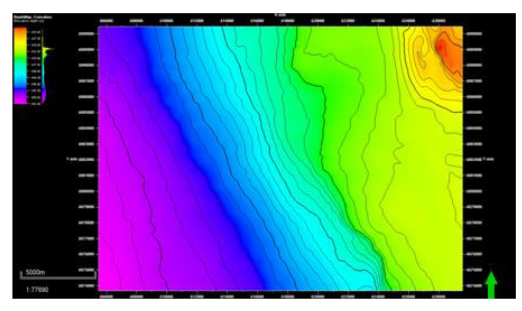

C

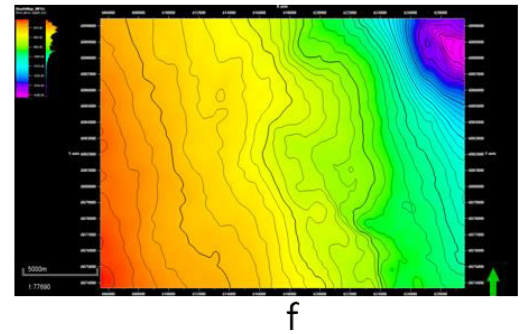

Figure 14. Depth Map Structure; (a) FS8; (b) FS7; (c) TRUNCATION; (d) TOP-FORESET; (e) FS6; and (f) MFS4

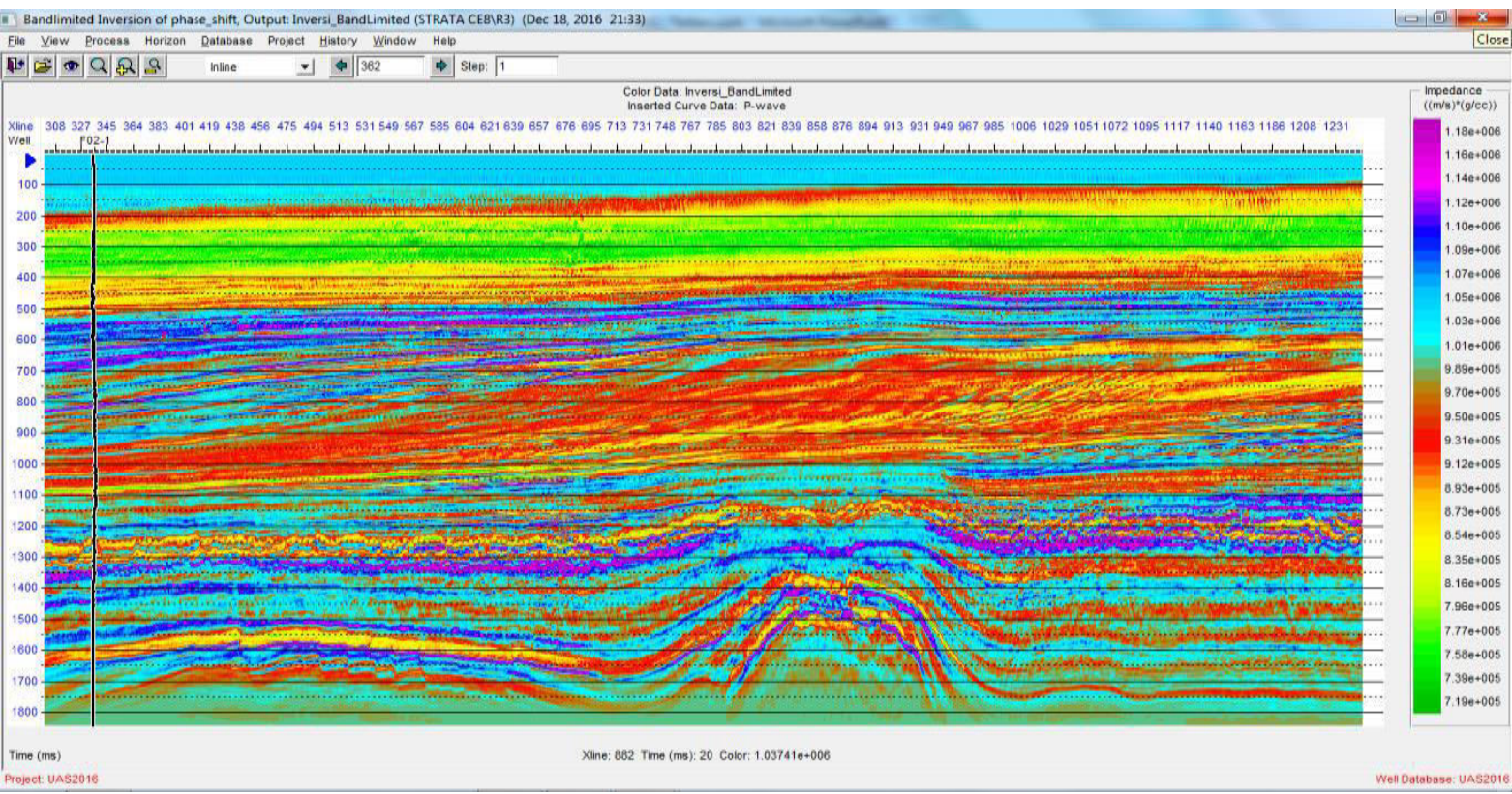

Figure 15. Band-Limited Inversion 
The Third International Conference on Civil Engineering Research (ICCER) August $1^{\text {st }}-2^{\text {nd }}$ 2017, Surabaya - Indonesia

In this study use the band-limited inversion method. This method purpose to obtain the subsurface sections of the seismic data. This inversion will assist in the process of analyzing and re-determain the hydrocarbon prospect zone. This inversion process is performed by utilize the horizon that has picked then determined initial model in accordance with the horizon. The inversion results can be seen in figure 15.
Prospect zone analysis use considerations from some result, such as the utilization of RMS Amplitude seismic attribute for hydrocarbon zone analysis, then crossplot analysis between density and porosity of well data. As in this RMS Amplitude analysis, the hydrocarbon prospecting zone is shown in the figure 32 and figure 33 in which the proposed interest zone is marked a yellow and red circle.

Overall we can see in the target zone that show

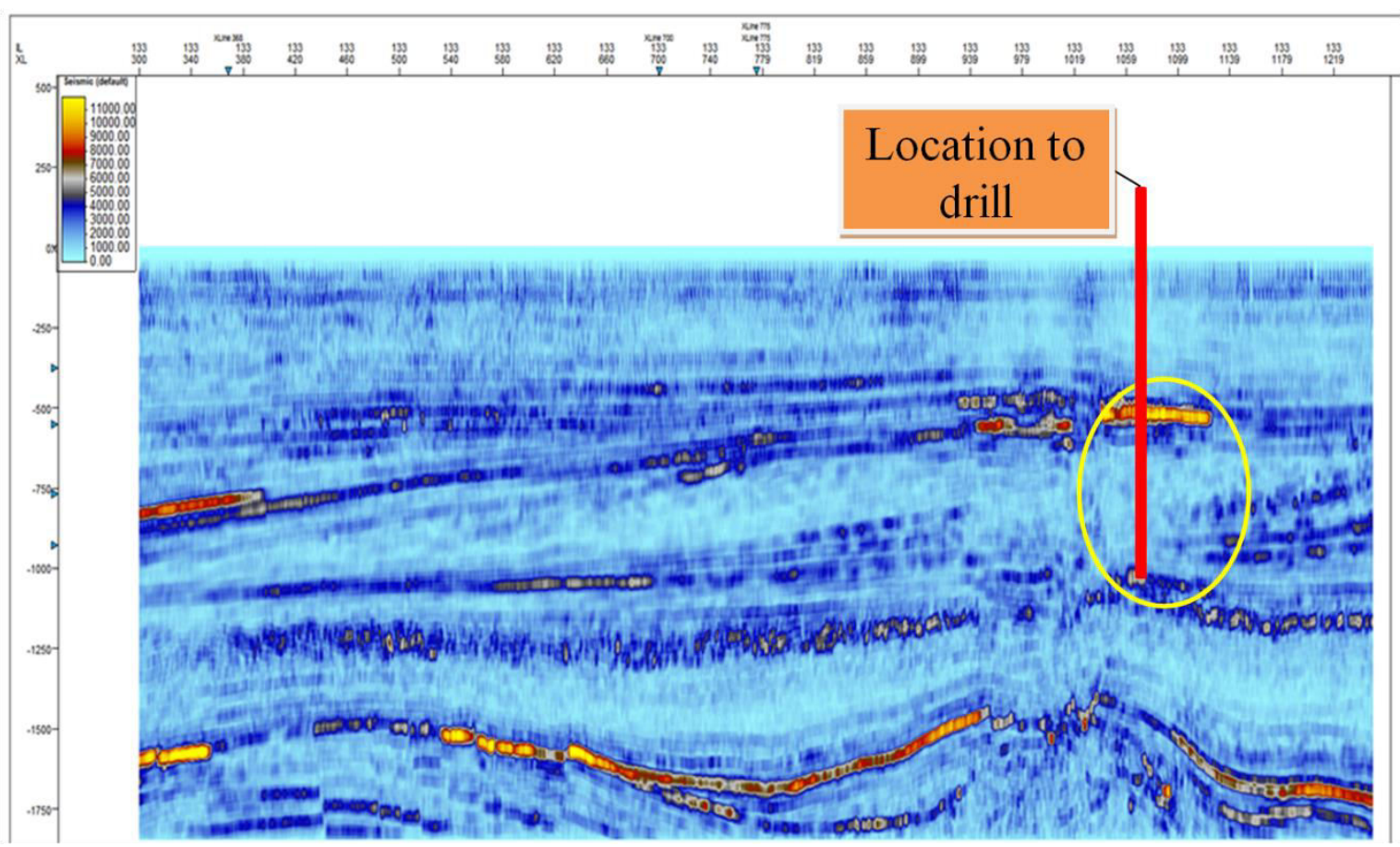

Figure 16. Vertical Display

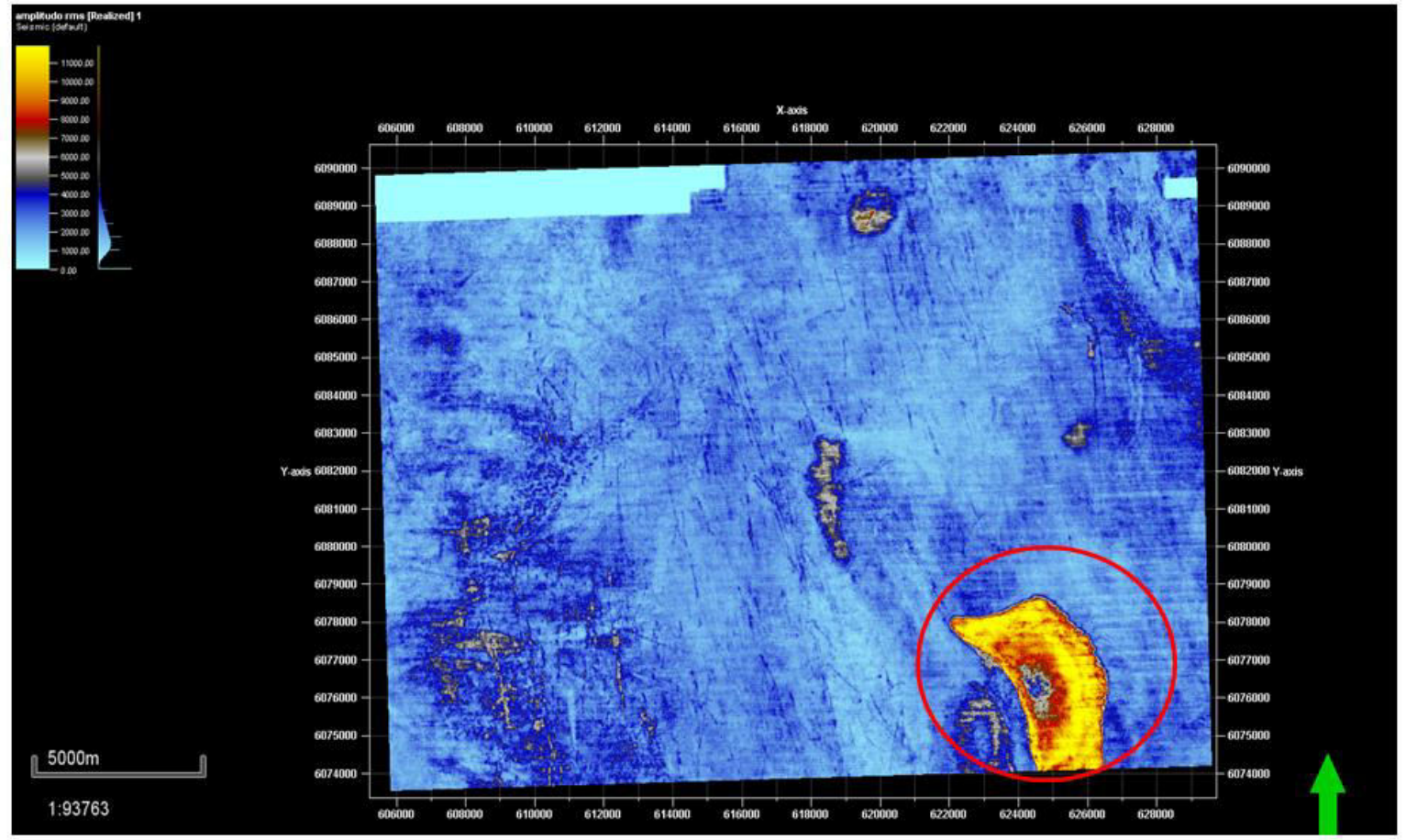

Figure 17. Horizontal Display

\subsection{Redefining the Prospect Zone}

as reservoir. This prospect zone can be characterized by using seismic attributes. While the contents of the 
reservoir can be determined from well data analysis. Based on the results of clay volume analysis with Gamma Ray as input parameters, it can be seen that the well that has the greatest prospect is the well F021 (774-919 meters) and F06-1 (770-825 meters). It is because the volume of sand in the prospect zone at both well is greater than the other two wells.

Amplitude RMS is an attribute that describes the amplitude value based on the attribute volume value. According to the results obtained RMS amplitude can map the presence of hydrocarbon distribution.

The determination of the prospect zone is supported by the presence of a fault zone aound the reservoir which can be assumed as a hydrocarbon migration path from the bottom. The fracture shown can be seen in the previous figure. The indicated prospect zone indicates as brighspot which is lithologically shaly sand as a gas reservoir.

\section{CONCLUSION}

The conclusions that can be drawn from this research are:

1. Based on the results of clay volume analysis with Gamma Ray as input parameters, it can be seen that the well that has the greatest prospect is the well F02-1 (774-919 meters) and F06-1 (770-825 meters). This is because the volume of sand in the prospect zone at both well is greater than the other two wells.

2. Depth of hydrocarbon target located at time domain form 250 to 500 second (time map structure) or 550 meter (depth conversion) with reservoir lithology of shaly sand containing gas fluid as fill.

\section{AKNOWLEDGMENTS}

The author praised the Thank you to Allah SWT who has bestowed many of His grace and guidance so that this research can be resolved. Thank you as much as the authors want to say to the Exploration Laboratory Department of Geophysical Engineering, and Department of Geophysical Engineering Sepuluh Nopember Institute of Technology. Acknowledgments are also intended for opendtect.com which has provided open source data to make it easier for writers to get data. The authors also thank the colleagues who have helped and take the time to process data in the field.

\section{REFERENCES}

[1] Agun, Satryo. 2007. Bab II: Teori Dasar Struktur Sesar dan Interpretasi pada Data Seismik Refleksi 3D, Laporan Tugas Akhir: Institut Teknologi Bandung.

[2] Brown, Alistair R. 2010. Interpretation of ThreeDimensional Seismic Data. Dallas: AAPG dan SEG.

[3] ITB Course. 2002. Interpretasi Seismik Geologi. Bandung: Institut Teknologi Bandung.

[4] Noor, Djauhari. 2009. Pengantar Geologi: Bab 7 - Geologi Struktur.
[5] Schlumberger Course. 2010. Seismic Introduction Fundamentals Presentation.

[6] Sukmono, Sigit. 2005. Seismic Methods for Field Exploration \& Developments Volume 1 and 2. Bandung: ITB.

[7] Sukmono, Sigit. 2007. Fundamental of Seismic Interpretation, Dept. of Geophysical Engineering. Bandung: ITB. 